\title{
An Empirical Study on Vocabulary Learning Strategy for Non-English Majors Based on Category Related Theories
}

\author{
Hanhan CHENG \\ City College, Wuhan University of Science and Technology, Wuhan, 430083, China \\ E-mail:16340470@qq.com
}

\section{Key words: Category Theory; Vocabulary, Learning Strategies; English Teaching}

\begin{abstract}
: vocabulary study plays a significant role in language learning as well as teaching process. In the Chinese academic setting, a large number of college students have lots of difficulty in memorizing new words but easily forgetting those words they already learnt quickly. This thesis provides data and experience to support the fact that due attention should be paid to heightening English vocabulary learning, and meantime, tentative suggestions would be given for English vocabulary teaching. Thus the main purpose of this thesis is to probe into English vocabulary in its theory, do an empirical study and apply certain cognitive linguistic researches into vocabulary learning and teaching in order to solve the problem of how to memorize vocabulary effectively.
\end{abstract}

\section{Introduction}

As the basis of language learning, vocabulary takes a significant part in the four language skills including listening, speaking, reading and writing, as well as a difficult learning process or task for language learners all the time. [1] It is vocabulary that is of great importance in each stage of any language or second language learning. Since the 1970s, many foreign scholars have studied on second language learning, such as O'Malley and Chatom, Atkinson and Rubin. [2] And they have carried out researches and work out some learning strategies like meta-cognitive method, cognitive method and social-affective method. Domestic scholars such as Wen Qiufang, Shu Dingfang and Wang Wenyu have put forward some viewpoints after some related studies, but vocabulary learning ability of English learning students in college are not improved obviously, and teachers mostly do not have, or lack or find it difficult for them to offer students proper methods or strategies of vocabulary learning and memorizing effectively. [3] Many English learners are faced with the challenge of how to memorize vocabulary and enlarge vocabulary in English language. In the recent years, many researchers have suggested that inferring and consulting dictionary should be paid more attention than memorizing new words directly to enlarge vocabulary size. In the recent years, many researchers have suggested that inferring and consulting dictionary should be paid more attention than memorizing new words directly to enlarge vocabulary size. [4] According to prototype category and basic-level category theory and other learning strategies, this study treats college non-English majors as participants and conduct an empirical experiment for the validity of vocabulary learning strategies or models which are obtained through applying category related theories into vocabulary learning. It is urgent for English teachers in college to develop students' awareness of using vocabulary learning strategies, especially under category theories to create enough opportunities to practice positive strategies effectively. Thus the main purpose of this thesis is to probe into English vocabulary in its theory, do an empirical study and apply certain cognitive linguistic researches into vocabulary learning and teaching in order to solve the problem of how to memorize vocabulary effectively. [5] This thesis is intended to get to know more about difficulties that exist in students' vocabulary learning and apply the category theories concerned to memorizing words of second language together with some part of regnant theories of vocabulary learning, and also come up with some strategies on the basis of the category theories concerned, which can help normal learners to memorize vocabulary more effectively and remember them for longer time. 


\section{Literature Review}

Classical category theory is a very traditional category theory formed more than two thousand years ago, in the period between Aristotle and Wittgenstein. [6] It is originated from Aristotle's book 'The Category. Construction and characteristics distinguish classical and prototype category theories and reveal diachronic development of category theory. It is Eleanor Rosch(1976) who first provides a general perspective on all these problems. She develops what has come to be called 'the theory of prototypes and basic-level categories', which include two dimensions: the vertical dimension concerns the level of inclusiveness of the category - the dimension along with which the terms collie, dog, mammal, animal, and living thing vary. The horizontal dimension concerns the segmentation of categories at the same level of inclusiveness - those which refer to chair, table, and bed vary. In doing so, E. Rosch provides a full-scale challenge to the classical theory and does more than anyone else to establish categorization as a subfield of cognitive psychology. After Wittgenstein, some scholars such as Berlin, Kay, Labov, Rosch, Mervis and Brown have developed family resemblance principle into 'prototype category theory'. Some scholars criticize the classical category theory and come up with their own viewpoints, especially American psychologist Rosch. Rosch has gradually found prototype category theory in which typical sample is to be cognitive reference. This theory is the application and development of Wittgenstein's family resemblance. The other explanation is that a prototype doesn't point to one concrete sample, but schematic representation based on the abstract to all members in this category. [7] Ungerer \& Schmid(1996:39) see this kind of abstract prototype as mental representation and cognitive reference. Prototypicality refers to the fact that category is based on prototypical members. Prototype is ideal in the center of its category which owns the most discrimination and information, and is the most familiar to people. Reed(1972) believes that prototype represents the average features and centralized tendency. Taylor (1989) believes that prototype is the schema representation of the core category concept. A comparison has been made by Ungerer and Schmid between superordinate category and the basic-level category and an explanation has been put forward that basic-level category is a prototype category and superordinate category is a family resemblance category.

It has been a long time since modern linguistics focused on vocabulary studies. At the beginning of the $1970 \mathrm{~s}$, the studies on language learning strategies were started out of a predominantly teaching-oriented perspective, but, it has been increasingly and dramatically believed in recent years that learners' interests and strategies have much effect on their language learning. Wong-Fillmore(1976), Tarone(1977), Bialystok(1978), Naimna et al.(1978), According to Cohen and Aphek(1980), Politzer and McGroarty(1985), Wenden(1986), Chamot and O'Malley(1987), they believed that aptitude is not the main reason governing the language learning, but the individual efforts that have more influence on learning. [8] Cohen and Aphek(1981) put forward that most learners only want to memorize the unknown words. Ahmed(1989) found that most of different learners mark on words or on margins of book pages. Politzer and McGroarty(1985) warn that whether learning strategies are good or bad depends on the context. a variety of studies on vocabulary learning strategy have come out in western countries. Imagery indicated by Norbert Schmitt is used effectively in vocabulary learning. New word can be connected with a lively personal experience of the latent concept. Besides the learning strategies talked above, there are many other strategies used in language learning and teaching. In China, there are many linguists and scholars contributing to studies on the English vocabulary acquisition including Wen Qiufang, Shu Dingfang, Wang Rongpei and so on. And, some studies are carried out by Chinese scholars such as "Belief, Strategy and English Vocabulary Memorization" written by Wang Wenyu(1998); 'Non-English Majors' Vocabulary Strategies' written by Wu Xia and Wang Qiang(1998); 'Mnemonic Approaches to English DifficultWords: investigation and analysis' written by Lu Wenpeng(2001). vocabulary problems perplexing English language learners may be solved sooner. With the help of a category hierarchy theory, students can find out and learn further the superordinate and subordinate words and phrases corresponding to the words and phrases they have learnt, and then, they can organize a knowledge network in mind to memorize words. 


\section{Methodology}

\section{A. Research Questions}

a. What is the current situation of English vocabulary learning strategies used by Chinese college students?

b. Does the application of category related theories have positive and efficient influence on vocabulary learning?

c. What vocabulary learning strategies or models based on the category related theories can be applied by college students to improve their English vocabulary acquisition?

\section{B. Participants}

The participants involved in the empirical research are from two classes in Grade 2014 in Wuhan University of Science and Technology, with 60 students coming from College of Economics and Management.

\section{Instruments}

The questionnaire is applied to measure situations and conditions of vocabulary learning strategies before the application of the ones under the category related theories. And the SPSS software will be used for statistical analysis of data after the experiment.

\section{Data Analysis and Discussion}

\section{A. Analysis and Discussion of Questionnaires}

There are three different choices for each question which accordingly equal to three grade scores. The score is got like 3 points for A, 2 points for $\mathrm{B}$ and 1 point for $\mathrm{C}$. The average represents the tendency of students in choosing items, or even the attitude for the question. In the experimental class, the average score of the first question is 1.27 points and in the control class is 1.40 . A comparatively large number of students want themselves to be taught with the basic meaning of a word, then they can easily know its meaning in a phrase or a specific sentence.

\section{B. Analysis and Discussion of Pre-test and Post-test}

Table1 T-test Comparison of Tests Scores between Two Classes

\begin{tabular}{|c|c|c|c|c|c|c|}
\hline \multirow{2}{*}{ Classes } & \multicolumn{2}{|c|}{ Mean } & \multicolumn{2}{c|}{ Standard Deviation } & \multicolumn{2}{c|}{ Sig(2-tailed) } \\
\cline { 2 - 7 } & Pre-test & Post-test & Pre-test & Post-test & Pre-test & Post-test \\
\hline Experimental & 62.67 & 76.63 & 3.24 & 5.3 & 0.29 & 0.023 \\
\hline Control & 63 & 70 & 3.37 & 5.9 & & \\
\hline
\end{tabular}

The table 1 reveals that the data is analyzed as follows: in the pre-test, the students of the two classes have similar mean scores in which one is 62.67 and the other one is 63 ; as for the standard deviation of the experimental class is 3.24 compared to that of the control class is 3.37; The p-value of the pre-test is 0.29 , at the probability level $(\mathrm{P}>0.05)$. While in the post-test, the p-value is 0.023 , $(\mathrm{P}=0.023<0.05)$, which indicates that the difference gradually appears in the mean scores of the two classes. To sum up, the whole students in the experimental class perform in English vocabulary learning better than those in the control class.

\section{Analysis and Discussion of the Test after Post-test}

Table 2 Independent-Sample T Test Result

\begin{tabular}{|l|l|l|l|l|l|}
\hline Group & Mean & SD & Min. & Max. & Sig(2-tailed) \\
\cline { 1 - 5 } Experimental & 45.70 & 6.325 & 35 & 57 & \multirow{2}{*}{0.03} \\
\cline { 1 - 3 } & 36.30 & 7.463 & 20 & 51 & \\
\hline
\end{tabular}

The figure of Sig (2-tailed) $=0.03<0.05$ reveals that students in the two groups performed dramatically differently. All the figures can give out distinct information that prototype category theory and basic-level category theory and the involved contribute to improving second language learners' vocabulary learning efficiency. The fact that students in the experimental class gradually 
perform better than those in the control class and data analysis in the post-test show the validity and effectiveness of the category theory applied to vocabulary learning.

\section{Conclusion}

It is obvious that basic-level vocabulary plays an important role in vocabulary memorization. From input through output angles, in most of students' writing works, basic-level vocabulary frequently takes up even more than $60 \%$, so, students who could master method of applying the basic words plus right word spelling are for certain to achieve a better communicative effect. It can be found out from the questionnaire that most students do not know much effective learning strategies in English vocabulary acquisition, and it follows that some teachers do not pay enough attention to vocabulary teaching. On the whole, after the training of the category theories from theory into practical application in teaching, students in the experimental class obviously performed much better in vocabulary learning in understanding, memorizing and motivational building-up, as in the process of this study. The major findings after the statistics of experiment data are shown as follows: Firstly, students, in mostly traditional vocabulary learning process, tend to apply such vocabulary learning strategies as rote learning, or word memorizing by spelling in an alphabetic order which are of low efficiency and bring about difficulties in enlargement of vocabulary. Secondly, in general, college non-English majors hardly make use of learning strategies directed under category theories to support themselves to improve vocabulary learning efficiency, and the ways of guessing word meaning through context and words association are unusually utilized. Thirdly, there exists a significant difference in application of vocabulary learning strategies and final scores of the tests between experimental and control classes after different vocabulary learning strategies are given to participants. They have a better understanding of the words category and classify the words into different categories, which may be viewed as a model to help them to memorize more vocabulary.

\section{References}

[1] F. Ungerer, H.J.Schmid. An Introduction to Cognitive Linguistics[M]. Foreign Language Teaching and Research Press. 2005.

[2] A Mobile Learning System with Question-Posing Strategy for Enhancing English Vocabulary Performances [A]. Lecture Notes in Information Technology-Proceedings of 2012 2nd International Conference on Future Computers in Education (ICFCE 2012) [C]. 2012

[3] Cuiqiong Pan,Lina Chi. A Networks-Tech Based Model to Management of English Vocabulary Teaching[A]. Proceedings of 2012 International Conference on Computer Science and Artificial Intelligence(CSAI 2012)[C]. 2012

[4] Jan H.Hulstijn,BatiaLaufer. Some Empirical Evidence for the Involvement Load Hypothesis in Vocabulary Acquisition [J]. Language Learning. 2008 (3)

[5] JoeBarcroft. Semantic and Structural Elaboration in L2 Lexical Acquisition[J]. Language Learning . 2008 (2)

[6] BatiaLaufer,T. SimaParibakht. The Relationship Between Passive and Active Vocabularies: Effects of LanguageLearning Context[J]. Language Learning. 2008 (3)

[7] Yuri Nagira. Vocabulary Learning through Captions [A]. The Proceedings of 2011 International Conference on Languages, Literature and Linguistics[C]. 2011

[8] Lijun Yang. The Influence of Extensive Reading upon Vocabulary Acquisition [A]. Proceedings of the International Conference on Education, Language, Art and Intercultural Communication (ICELAIC 2014) Part B[C]. 2014 